\title{
The Potential for Cloth Masks to Protect Health Care Clinicians From SARS-CoV-2: A Rapid Review
}

\author{
Ariel Kiyomi Daoud \\ Jessica Kole Hall \\ Haylie Petrick \\ Anne Strong \\ Cleveland Piggott, MD, MPH \\ Department of Family Medicine, University \\ of Colorado School of Medicine, Aurora, \\ Colorado
}

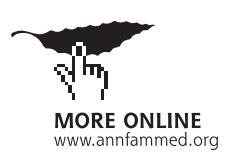

Conflicts of interest: authors report none.

\section{CORRESPONDING AUTHOR}

Cleveland Piggott

Department of Family Medicine

University of Colorado School of Medicine 13001 E 17th Pl

Aurora, CO 80045

Cleveland.Piggott@cuanschutz.edu

\begin{abstract}
PURPOSE The coronavirus disease 2019 (COVID-19) pandemic has led at times to a scarcity of personal protective equipment, including medical masks, for health care clinicians, especially in primary care settings. The objective of this review was to summarize current evidence regarding the use of cloth masks to prevent respiratory viral infections, such as severe acute respiratory syndrome coronavirus 2 (SARS-CoV-2), among health care clinicians.
\end{abstract}

METHODS We searched 5 databases, the Centers for Disease Control and Prevention website, and the reference lists of identified articles on April 3, 2020. All identified publications were independently screened by 2 reviewers. Two authors independently extracted data and graded the studies. Randomized control trials (RCTs) were graded using the Consolidated Standards of Reporting Trials (CONSORT) checklist, and observational and nonhuman subject studies were graded using 11 domains common across frequently used critical appraisal tools. All discrepancies were resolved by consensus.

RESULTS Our search identified 136 original publications. Nine studies met inclusion criteria. We performed a qualitative synthesis of the data from these studies. Four nonrandomized trials, 3 laboratory studies, 1 single-case experiment, and 1 RCT were identified. The laboratory studies found that cloth materials provided measurable levels of particle filtration but were less efficacious at blocking biologic material than medical masks. The RCT found that cloth masks were associated with significantly more viral infections than medical masks.

CONCLUSIONS The current literature suggests that cloth materials are somewhat efficacious in filtering particulate matter and aerosols but provide a worse fit and inferior protection compared to medical masks in clinical environments. The quality and quantity of literature addressing this question are lacking. Cloth masks lack evidence for adequate protection of health care clinicians against respiratory viral infections.

Ann Fam Med 2021;19:55-62. https://doi.org/10.1370/afm.2640.

\section{INTRODUCTION}

In December 2019, the novel coronavirus, severe acute respiratory syndrome coronavirus 2 (SARS-CoV-2), emerged in Wuhan, China and quickly became a global pandemic as the coronavirus disease 2019 (COVID-19) respiratory syndrome. At the time of this article's writing, more than 68 million cases were reported worldwide, with more than 1,500,000 deaths. ${ }^{1}$ In the United States, health care clinicians have been faced with a scarcity of personal protective equipment (PPE) including N95 respirators and disposable medical masks. ${ }^{2}$ As the United States has focused primarily on supporting large urban hospitals to care for the surge of severely ill patients, primary care offices have experienced severe PPE shortages. ${ }^{3}$ During the week of this article's writing in April 2020, 58\% of primary care clinicians reported in a national survey to have resorted to the use of homemade and/or used PPE. Seven months later, 32\% reported that they were either lacking PPE or felt that their required level of PPE reuse was unsafe. ${ }^{4}$ 
Hospitals, health care systems, and the National Strategic Stockpile have insufficient supply to provide adequate PPE for health care clinicians. This leaves primary care practices and other resource-limited organizations, such as rural hospitals, to determine how to protect their clinicians. Conflicting information from the popular media, messaging from various health care systems, and constantly changing societal guidelines complicate decisions regarding appropriate mask usage in clinical settings during times of scarcity. Creative solutions include rationing supplies, extending the use of PPE, recycling masks, and devising alternative face protection. ${ }^{2}$ The US Centers for Disease Control and Prevention (CDC) states that health care clinicians may used cloth masks as a last resort. ${ }^{5}$ The CDC notes that cloth masks are not considered PPE and that their capability to protect health care clinicians is not currently known. The CDC does not offer information regarding the degree of protection a cloth mask might provide compared to a medical mask. In addition, there is no recommendation for what the best design of a cloth mask might be in the face of a shortage of PPE. This rapid review summarizes current evidence on the efficacy and effectiveness of cloth masks compared with medical masks to prevent respiratory viral infections among health care clinicians.

\section{METHODS}

\section{Criteria for Study Consideration}

We followed Cochrane rapid review methods for this review. ${ }^{6}$ We included all studies examining the efficacy and/or effectiveness of cloth masks in filtering biologic materials or comparing a cloth mask to an industrial medical or surgical mask. Efficacy refers to the performance of mask materials in a laboratory setting (ie, filtration, fit factor, pressure gradient), whereas effectiveness considers the performance of masks when used by human subjects in clinical environments (ie, infection rate). Biologic materials were defined as bacteria or viruses. The term cloth was applied broadly and included any type of woven nonsynthetic material or woven polyester fabric that might be used to create a homemade cloth mask. Studies examining filtering ability of cloth masks against environmental exposures, such as diesel particles, foundry exposure, welding fumes, or pollution, were excluded. Reviews, opinion pieces, letters to the editor, commentaries, research briefs, and anecdotes were also excluded.

\section{Main Outcome Measures}

Inclusion in this review required at least 1 of the following outcome measures:
- Efficacy or effectiveness of cloth masks

- Respiratory illness/infection rate of health care clinicians wearing cloth masks

- Filtration efficiency of cloth masks compared to medical or surgical masks

- Percentage aerosol penetration of cloth masks compared to medical or surgical masks

- Comparison of mask fit between cloth and medical or surgical masks

\section{Search Methods}

We performed a search of MEDLINE, the Cochrane Library, Embase, the Cumulative Index to Nursing and Allied Health Literature (CINAHL), and the Web of Science databases on April 3, 2020, to identify relevant studies for this review. Gray literature was searched briefly via the CDC's website. Reference lists of identified studies were consulted for additional publications. Publication dates before 1970 were not considered. No exclusion criteria were applied on the basis of study quality grade or language. A health science librarian was consulted for the identification of appropriate databases and assistance with search term definitions. See Supplemental Table 1, https://www.AnnFamMed. org/content/19/1/55/suppl/DC1/, for search strategies.

\section{Data Collection and Analysis}

\section{Study Selection}

All studies retrieved via database searches were downloaded to citation manager software. Duplicates were removed. Two authors (JKH and AS) independently screened identified studies via title and abstract content and then independently reviewed full-text publications of the screened studies. Any discrepancies in eligibility were resolved via discussion and consensus between the independent reviewers and additional authors as needed.

\section{Data Extraction and Management}

Two authors (HP and AKD) independently extracted data from the final list of eligible studies to separate spreadsheets. Data were compared and discrepancies resolved via discussion and consensus, including additional author(s) as necessary. They then independently appraised each study and resolved discrepancies via discussion and consensus. Study appraisal was implemented to identify flaws in methodology and assess bias. Randomized control trials (RCTs) were appraised using the Consolidated Standards of Reporting Trials (CONSORT) checklist. ${ }^{7}$ The diversity of study type included prevented implementation of a single critical appraisal tool. Reviewers considered observational and nonhuman subjects studies using 11 domains common across frequently used critical appraisal tools. ${ }^{8}$ 


\section{RESULTS}

\section{Publication Identification}

Our search of 5 databases and gray literature yielded 136 nonduplicate original publications (Figure 1). Ten of the publications required title or available abstract translation from non-English languages; all were irrelevant to our study question and were excluded. Thirty-six articles were identified for full-text evaluation, and 27 were excluded (Supplemental Table 2, https://www.AnnFamMed.org/content/19/1/55/suppl/ DC1/). Nine studies were included for analysis after screening and selection. Four nonrandomized trials, 3 laboratory efficacy studies, 1 single-case experiment, and 1 RCT were included.9-17 We excluded several studies that investigated cloth mask protection against air pollution or industrial debris. Although those studies might provide insight regarding physical characteristics of cloth materials, we chose to include only studies that explicitly considered mask use to prevent disease or measured particles of biologic significance such as bacteria, viruses, or particles intended to be of similar size to respiratory droplets or aerosols.

Overall quality assessment and appraisal details of the observational and nonhuman subject studies are summarized in Table 1 . The 11 domains $^{8}$ for which each study was considered were not equally weighted for determination of overall study quality. The low-quality studies ${ }^{15,16}$ had small trial numbers, did not report statistical significance, failed to address potential sources of bias, and did not report funding sources. The moderate-quality studies ${ }^{13,14}$ had higherquality methods but did not fully discuss limitations. The most-commonly neglected criterion among the high-quality studies ${ }^{9-12}$ was lack of a no-mask control for comparison with cloth masks. We considered these appraisal findings when reporting results and drawing conclusions from each publication.

The 9 studies that met inclusion for analysis were then appraised (Table 2). ${ }^{9-17}$ The RCT by MacIntyre et $\mathrm{al}^{17}$ closely followed CONSORT guidelines but notably did not include a control group without masks, owing to the clinical setting. In addition, the authors disclosed a former relationship with $3 \mathrm{M}$, which produces commercial masks. Although they reported that $3 \mathrm{M}$ was not involved in their RCT, it remains a source of potential bias.

\section{Filtration}

Seven publications addressed the filtration efficacy of commercial cloth masks or materials used to create homemade masks, such as polyester, cotton, tea towel, and scarves, in a laboratory setting. ${ }^{9-11,13-15,17}$ These studies used various experimental techniques
Figure 1. Study flowchart for selection of articles.

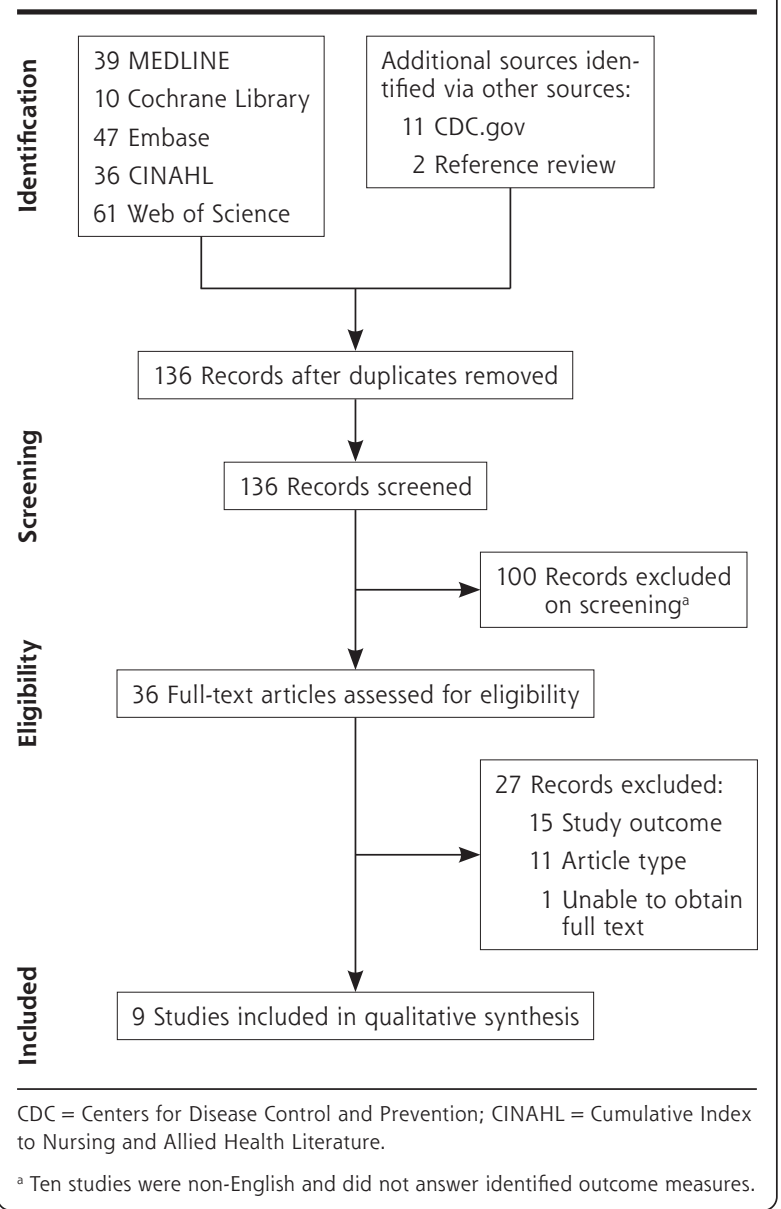

to investigate filtration of aerosolized virus, ${ }^{9,14}$ aerosolized particles, ${ }^{11,17}$ or bacteria. ${ }^{9,10,13,15}$ Of the studies that evaluated pathogen penetration, 4 detected viable pathogens via colony formation, $9,10,13,15$ and 1 detected postfiltration virus via polymerase chain reaction (PCR). ${ }^{14}$ Regardless of the filtered substance or detection method, all concluded that cloth materials prevent some level of penetration but generally had lesser filtration efficiency and greater variability than medical masks. These findings suggest some, though highly variable, filtration by cloth mask materials.

Two of the identified studies investigated the effect of multiple layers of material on viral filtration. ${ }^{9,14}$ Both reported that use of multiple layers increased the viral filtration efficacy of cloth mask material. Ma et al also specifically selected experimental material for physical similarity to SARSCoV-2. ${ }^{14}$ That study concluded that 1 layer of polyester combined with 4 layers of paper towel was similarly efficacious to a medical mask. ${ }^{14}$ Both types of mask, polyester alone and combined with paper 
Table 1. Observational and Nonhuman Subjects Study Appraisal Results

\begin{tabular}{|c|c|c|c|c|c|c|}
\hline Publication & Study Type & $\begin{array}{c}\text { Overall } \\
\text { Study } \\
\text { Assessment }^{\mathrm{a}}\end{array}$ & $\begin{array}{l}\text { Appropriate } \\
\text { Study } \\
\text { Design }\end{array}$ & $\begin{array}{l}\text { Prospective } \\
\text { Calculation } \\
\text { of Study Size }\end{array}$ & $\begin{array}{l}\text { Blinding of } \\
\text { Patients and } \\
\text { Personnel }\end{array}$ & $\begin{array}{c}\text { Patient } \\
\text { Selectionl } \\
\text { Inclusion Criteria }\end{array}$ \\
\hline Davies et al ${ }^{9}$ & Nonrandomized trial & High & Yes & No & No & Yes \\
\hline Liu et $\mathrm{al}^{10}$ & Nonrandomized trial & High & Yes & No & No & No \\
\hline Rengasamy et al'11 & Laboratory efficacy study & High & Yes & No & No & $\ldots$ \\
\hline van der Sande et al ${ }^{12}$ & Nonrandomized trial & High & Yes & No & No & No \\
\hline Furuhashi ${ }^{13}$ & Laboratory efficacy study & Moderate & Yes & No & No & $\ldots$ \\
\hline Ma et al ${ }^{14}$ & Laboratory efficacy study & Moderate & Yes & No & No & $\ldots$ \\
\hline Quesnel ${ }^{15}$ & Single-case experiment & Low & Yes & No & No & No \\
\hline Sellers et al ${ }^{16}$ & Nonrandomized trial & Low & Yes & No & No & Yes \\
\hline
\end{tabular}

towel, blocked $\sim 95 \%$ of viral particles similar in size to SARS-CoV-2, as detected by PCR. However, the authors of the study considered this insufficient protection for health care clinicians and suggested use of N95 respirators. ${ }^{14}$

\section{Fit and Airflow}

Four studies investigated fit, particle leakage, or airflow of cloth masks in human volunteers. . $^{9,10,12,16}$ One study used a commercial fit-testing system for cloth masks that were constructed and worn by volunteers, ${ }^{9}$ and

Table 2. Summary of Included Studies

\begin{tabular}{|c|c|c|c|c|c|c|c|}
\hline \multirow{2}{*}{\multicolumn{4}{|c|}{ Characteristics }} & \multicolumn{4}{|c|}{ Outcomes } \\
\hline & & & & \multicolumn{3}{|c|}{ Efficacy ${ }^{a}$} & \multirow{2}{*}{$\frac{\text { Effectiveness }^{\mathrm{b}}}{\text { Infection }}$} \\
\hline Publication & Study Type & Population & Pathogen/Particle & Filtration & Fit & Airflow & \\
\hline $\begin{array}{l}\text { Maclntyre } \\
\text { et al }{ }^{17}\end{array}$ & $\begin{array}{l}\text { Randomized } \\
\text { trial }\end{array}$ & $\begin{array}{l}\text { Health care clinicians in } \\
\text { high-risk wards in Viet- } \\
\text { nam }(N=1,607)\end{array}$ & $\begin{array}{l}\text { Viral respiratory } \\
\text { infection,c aerosol- } \\
\text { ized particles }\end{array}$ & $\begin{array}{l}\text { Cloth }< \\
\text { medical }\end{array}$ & $\ldots$ & $\ldots$ & $\begin{array}{c}\text { Cloth }<\text { medical } \\
\left(\begin{array}{c}\uparrow \text { infection in } \\
\text { cloth })\end{array}\right.\end{array}$ \\
\hline Davies et al ${ }^{9}$ & $\begin{array}{l}\text { Nonrandomized } \\
\text { trial }\end{array}$ & $\begin{array}{l}\text { Volunteers, general popu- } \\
\text { lation }(\mathrm{N}=21)\end{array}$ & $\begin{array}{l}\text { Aerosolized virus, } \\
\text { aerosolized bacteriad }^{d}\end{array}$ & $\begin{array}{l}\text { Cloth }< \\
\text { medical }\end{array}$ & $\begin{array}{l}\text { Cloth }< \\
\text { medical }\end{array}$ & $\begin{array}{l}\text { Cloth }< \\
\text { medical }\end{array}$ & $\ldots$ \\
\hline Liu et al ${ }^{10}$ & $\begin{array}{l}\text { Nonrandomized } \\
\text { trial }\end{array}$ & Surgeons $(N=50)$ & Bacteria $^{d}$ & $\begin{array}{l}\text { Cloth }< \\
\text { medical }\end{array}$ & $\ldots$ & $\begin{array}{l}\text { Cloth }< \\
\text { medical }\end{array}$ & $\ldots$ \\
\hline Sellers et al ${ }^{16}$ & $\begin{array}{l}\text { Nonrandomized } \\
\text { trial }\end{array}$ & $\begin{array}{l}\text { Human subjects exposed } \\
\text { to hand-and-foot virus } \\
(\mathrm{N}=8)\end{array}$ & Picornaviruse & $\ldots$ & $\ldots$ & $\ldots$ & $\begin{array}{c}\text { Cloth = medical } \\
(\uparrow \text { infection in } \\
\text { both })\end{array}$ \\
\hline $\begin{array}{l}\text { van der Sande } \\
\text { et al }{ }^{12}\end{array}$ & $\begin{array}{l}\text { Nonrandomized } \\
\text { trial }\end{array}$ & $\begin{array}{l}\text { Volunteers, general popu- } \\
\text { lation }(\mathrm{N}=39)\end{array}$ & Particles $(0.02-1 \mu \mathrm{m})$ & $\ldots$ & $\begin{array}{l}\text { Cloth }< \\
\text { medical }\end{array}$ & $\ldots$ & $\ldots$ \\
\hline Furuhashi13 & $\begin{array}{l}\text { Laboratory effi- } \\
\text { cacy study }\end{array}$ & $\ldots$ & Bacteria $^{d}$ & $\begin{array}{l}\text { Cloth }< \\
\text { medical }\end{array}$ & $\ldots$ & $\begin{array}{l}\text { Cloth }< \\
\text { medical }\end{array}$ & $\cdots$ \\
\hline Ma et $\left.a\right|^{14}$ & $\begin{array}{l}\text { Laboratory effi- } \\
\text { cacy study }\end{array}$ & $\ldots$ & Aerosolized virus ${ }^{\uparrow}$ & $\begin{array}{l}\text { Cloth }= \\
\text { medical }\end{array}$ & $\ldots$ & $\ldots$ & $\ldots$ \\
\hline $\begin{array}{l}\text { Rengasamy } \\
\text { et al }{ }^{11}\end{array}$ & $\begin{array}{l}\text { Laboratory effi- } \\
\text { cacy study }\end{array}$ & $\ldots$ & $\begin{array}{l}\text { Aerosolized particles } \\
(20-1,000 \mathrm{~nm})\end{array}$ & $\begin{array}{l}\text { Cloth }< \\
\text { N95 }\end{array}$ & $\ldots$ & $\ldots$ & $\cdots$ \\
\hline Quesne ${ }^{15}$ & $\begin{array}{l}\text { Single-case } \\
\text { experiment }\end{array}$ & $\begin{array}{l}\text { Single human test subject, } \\
\text { general population }\end{array}$ & Bacteria $^{d}$ & $\begin{array}{l}\text { Cloth }= \\
\text { medical }\end{array}$ & $\ldots$ & $\ldots$ & $\cdots$ \\
\hline \multicolumn{8}{|c|}{ hMPV = human metapneumovirus; $\mathrm{PCR}=$ polymerase chain reaction. } \\
\hline \multicolumn{8}{|c|}{ Note: $<$ indicates less effective or efficacious; $=$ indicates no difference in effectiveness or efficacy; $\uparrow$ indicates increased incidence. } \\
\hline \multicolumn{8}{|c|}{$\begin{array}{l}\text { a Efficacy refers to the performance of mask } \\
\text { b Effectiveness refers to the performance of } \\
\text { ' Influenza-like illness and/or pharyngeal swa } \\
\text { d Viable pathogen detected via postfiltration } \\
\text { e Viral colony formation from nasal swab. } \\
\text { ' Virus detected via postfiltration PCR. }\end{array}$} \\
\hline
\end{tabular}




\begin{tabular}{|c|c|c|c|c|c|c|}
\hline $\begin{array}{c}\text { Subject } \\
\text { Comparability }\end{array}$ & $\begin{array}{c}\text { Appropriate } \\
\text { Endpoints }\end{array}$ & $\begin{array}{c}\text { Assessment } \\
\text { of Outcomes/ } \\
\text { Exposure }\end{array}$ & $\begin{array}{l}\text { Follow-Upl } \\
\text { Handling of } \\
\text { Missing Data }\end{array}$ & Reporting & Confounding & $\begin{array}{c}\text { Appropriate } \\
\text { Statistical } \\
\text { Analysis }\end{array}$ \\
\hline Yes & Yes & Yes & Yes & Yes & Yes & Yes \\
\hline Yes & Yes & Yes & Yes & Yes & Yes & Yes \\
\hline$\ldots$ & Yes & Yes & $\ldots$ & Yes & Yes & Yes \\
\hline Yes & Yes & Yes & Yes & Yes & Yes & Yes \\
\hline$\ldots$ & Yes & Yes & $\ldots$ & Yes & Yes & Yes \\
\hline$\ldots$ & Yes & Yes & $\ldots$ & Yes & Yes & Yes \\
\hline Yes & Yes & Yes & Yes & Yes & Yes & No \\
\hline No & Yes & Yes & No & No & No & Yes \\
\hline
\end{tabular}

another quantified fit by measuring inward particle leakage by homemade tea towel masks compared to medical masks. ${ }^{12}$ These investigations concluded that cloth masks provide a measurable barrier but have worse fit and a greater level of particle leakage compared to medical masks. ${ }^{9,12}$

Limited airflow through cloth materials can contribute to breathing difficulties and particle leakage. Thus, airflow is an important consideration in cloth mask design. Airflow was assessed in 2 studies with human subjects., ${ }^{9,10}$ The materials with the greatest filtration efficacy (vacuum bag and tea towel) were countered by very low airflow, which made breathing difficult and limits use of these materials. 9,10

\section{Infection Risk}

Two studies evaluated cloth mask effectiveness outside of laboratory conditions. ${ }^{16,17}$ The only RCT published to date reported the differences in infectious outcomes with standardized use of cloth masks, medical masks, and usual practice and called into question their effectiveness in clinical environments. ${ }^{17}$ Usual practice in that study included variable cloth mask use. Participants in that study arm were permitted to choose the type and duration of mask use throughout the study; therefore, there was no true unmasked control arm. Both intention-to-treat and post hoc analyses adjusting for compliance and confounders found greater rates of influenza-like illness (ILI) in the cloth mask arm compared to the medical mask arm. Of note, the relative risk of ILI was 13.25 , and the $95 \%$ CI ranged broadly, from 1.74 to 100.97 . Comparing participants from all arms who exclusively wore medical masks to those who only wore cloth masks, the incidences of ILI and laboratory-confirmed virus were significantly greater among health care clinicians who used cloth masks. The RCT's authors could not definitively determine whether these results reflected superior protection from medical masks or a harmful effect of cloth masks. Considering their prior findings of negligible effect of medical masks against viral infection compared to N95 respirators, ${ }^{18,19}$ and that the medical mask used had particularly poor filtration, they concluded that the increased incidence of ILI in cloth mask users might be due to a detrimental effect of cloth masks.

Sellers et al evaluated cloth mask effectiveness against the transmission of foot-and-mouth virus. ${ }^{16}$ That study compared viral transmission of foot-andmouth virus in exposed subjects wearing industrial gauze and cotton masks, cloth surgical masks, or paper masks. They concluded that the industrial and cloth masks minimally decreased total virus inhalation, and paper masks had no effect.

\section{DISCUSSION}

The current COVID-19 pandemic has at times caused a shortage of PPE worldwide. Communities across the United States have mobilized efforts to provide health care clinicians with homemade cloth masks ${ }^{20}$ as a reusable and accessible last-resort face covering. Primary care clinicians must decide how to protect themselves and their colleagues when adequate numbers of medical masks are not available. Several reports published during this pandemic addressed the effectiveness of cloth mask use in the community to prevent viral spread $^{21-25}$; however, the use of cloth masks for protection of health care clinicians has not been thoroughly explored. This rapid review identified the relevant literature and brings together the disparate variables 
of filtration, fit and airflow, and clinical effectiveness to evaluate the potential for cloth masks to protect health care clinicians.

\section{Filtration}

Our qualitative synthesis suggested that cloth materials provide a measurable level of particle filtration. On this basis alone, cloth masks are superior to complete lack of face protection. However, this cannot serve as reassurance of sufficient protection for health care clinicians. The level of filtration provided is highly variable and consistently inferior to standard medical masks. ${ }^{9-}$ ${ }_{11,13-15}$ Studies included in this review that considered protection for the wearer suggested that the filtration capabilities of cloth masks would not adequately protect health care clinicians against viral infection. ${ }^{12,14,17}$ For clinicians treating patients with COVID-19, it is notable that none of the studies in this review specifically tested SARS-CoV-2 transmission, and only 1 study selected experimental bioaerosols for physical similarity to SARS-CoV-2. ${ }^{14}$ In addition, conclusions regarding filtration were based on investigations of aerosolized particles including noncoronaviruses, ${ }^{9,11,14,16}$ bacteria ${ }^{8,13,17}$ and simulated biologic particles. ${ }^{12,15}$ According to the World Health Organization, contact and respiratory droplets are the primary method of SARS-CoV-2 spread, ${ }^{26}$ and aerosols are thought to play a smaller role. ${ }^{22}$ The majority of efficacy studies examined here investigate filtration of aerosolized particles or virus rather than droplet or contact protections. Thus, we must interpret these results with caution in the context of COVID-19.

\section{Fit and Airflow}

When considering a cloth mask as opposed to medical masks or a bandana or scarf, fit and airflow are essential elements to consider. These are also elements that distinguish medical masks from N95 respirators. Poor fit decreases protection because particles can pass through gaps between the wearer's face and the mask, while poor airflow causes breathing difficulty, causing compliance issues. ${ }^{9,14}$ No current studies compared variable designs of cloth masks for fit or airflow, but multiple studies showed inferior fit of cloth masks compared to medical masks. Two studies found that the studied designs and materials of cloth masks limit both proper fit and airflow, leading to decreased protection and breathing difficulties. ${ }^{8,14}$ This poses a significant challenge to cloth mask use and presents an opportunity for future research and development.

\section{Clinical Effectiveness}

Although multiple studies indicated that cloth masks might be somewhat efficacious, the single clinical investigation suggests that they provide inferior protection in clinical settings and might even increase risk to health care clinicians. Whereas that work suggested that clinicians should exercise caution when choosing to use cloth masks, there are no similar real-world studies to support or refute this conclusion and no investigations as to why cloth masks might have increased risk of viral infection. Although they considered poor filtration, moisture retention, ineffective cleaning, and reuse of cloth masks as possible contributors, the authors did not detail how health care clinicians used their 5 provided cloth masks over their 8 -hour shifts. This prevents conclusions regarding length of use and moisture retention. The authors noted that $80 \%$ of cloth mask wearers washed their masks at home with soap and water rather than in hospital-grade laundry. ${ }^{17}$ In addition, the RCT isolated buman metapneumovirus, rhinoviruses, and influenza B virus, which differ in transmission and pathogenic properties from SARS-CoV-2. ${ }^{21}$

\section{Strengths and Limitations}

To our knowledge, this is the only contemporary rapid review of cloth face masks specifically for health care clinician protection. Strengths of this rapid review include a comprehensive search of high-yield databases, in consultation with a health sciences librarian. Owing to the limited number of eligible articles, studies of all grade scores were included. This review excluded studies considering environmental contaminants such as diesel particles. The body of literature on environmental contaminants might provide additional insight regarding the protective qualities of cloth masks that were not addressed by this review. Other considerations, including virus viability on masks or mask materials and behavior change associated with mask use, lack definitive understanding. ${ }^{27}$ Given the lack of quantity and quality of literature available, this review cannot remark definitively on protection for health care clinicians from COVID-19 by cloth masks.

\section{Recommendations}

Current CDC guidelines recommend use of an N95 respirator for care of patients with COVID-19 because medical masks cannot provide the same level of protection against aerosolized particles. ${ }^{28}$ Whereas there is some evidence for SARS-CoV-2 aerosol transmission, ${ }^{22,26}$ protective measures against droplet transmission should also be considered. For a primary care clinician without access to medical masks, our qualitative synthesis of the literature suggests that it is better to wear a cloth mask than no mask but not without careful consideration of harm reduction. The psychologic theory of risk compensation refers to the concept that 
humans might behave less conservatively when they believe their risk to be decreased..$^{27}$ This is essential to consider when creating policies regarding the use of cloth masks and messaging to health care clinicians regarding their risks when wearing cloth masks.

We emphasize the CDC's recommendation of pairing cloth masks with a plastic face shield. ${ }^{5}$ Considering the findings of MacIntyre et $\mathrm{al}_{1}{ }^{17}$ it is important to address the potential for increased risk of viral infection to the wearer. We recommend frequent cloth mask changes to reduce the risk of moisture retention and washing according to hospital laundry standards to decrease the risk of ineffective cleaning. The rapidly evolving nature of research and literature regarding protective face coverings during the COVID-19 pandemic presents a challenge for those trying to stay up to date. The CDC has published a running list of studies on masks that might provide additional guidance for health care clinicians considering cloth masks. ${ }^{29}$

\section{CONCLUSIONS}

Review of the current literature suggests that cloth materials are somewhat effective in filtering particles and aerosols, but cloth masks provide inferior protection, with poorer fit and airflow, compared to medical masks. Some data also suggest a potential harm to health care clinicians using cloth masks for extended periods in the clinical setting. Cloth masks should not be considered equivalent to medical masks, and if clinicians choose to use them, level of fit, type of material, and number of layers should be considered. Overall, we conclude that cloth masks lack evidence for adequate protection of health care clinicians against viral respiratory infections, and health care clinicians should use caution when deciding whether to use cloth masks for extended clinical work.

Additional research is needed to provide a complete understanding of cloth mask effectiveness in health care environments. Future work should include systematic comparison of different cloth mask designs and cloth types against standard surgical masks and N95 respirators in a controlled laboratory setting to optimize fit and material properties. Additional RCTs are required to assess the realities of cloth mask use by health care clinicians.

To read or post commentaries in response to this article, see it online at https://www.AnnFamMed.org/content/19/1/55.

Key words: COVID-19; personal protective equipment; PPE; pandemic Submitted April 17, 2020; submitted, revised, July 20, 2020; accepted August 3, 2020.

Acknowledgments: We thank Kristen DeSanto, MSLS, MS, RD, AHIP, for support in designing search strategy and defining search terms, and Austin Jolly, BA, for editing support.
Supplemental materials: Available at https://www.AnnFamMed. org/content/19/1/55/suppl/DC1/.

\section{References}

1. World Health Organization. Coronavirus disease (COVID-19) pandemic. Published 2020. Updated Dec 12, 2020. Accessed Dec 12, 2020. https://www.who.int/emergencies/diseases/ novel-coronavirus-2019

2. Ranney ML, Griffeth V, Jha AK. Critical supply shortages - the need for ventilators and personal protective equipment during the Covid19 pandemic. N Engl J Med. 2020;382(18):e41.

3. Quick COVID-19 primary care survey: series 5, fielded April 10-13, 2020. Primary Care Collaborative and the Larry A. Green Center. Accessed Dec 9, 2020. https://static1.squarespace.com/static/5d7f f8184cf0e01e4566cb02/t/5e99a8c2d06cf505d38ac3cc/15871285 15653/C19+Series + 5 + National + Executive + Summary.pdf

4. Primary Care Collaborative and the Larry A. Green Center. COVID19 survey. Accessed Dec 11, 2020. https://www.pcpcc.org/covid

5. Centers for Disease Control and Prevention. Strategies for optimizing the supply of facemasks. Published 2020. Updated Nov 23, 2020. Accessed Dec 11, 2020. https://www.cdc.gov/coronavirus/ 2019-ncov/hcp/ppe-strategy/face-masks.html

6. Garritty C, Gartlehner G, Kamel C, et al. Cochrane Rapid Reviews. Interim guidance from the Cochrane Rapid Reviews Methods Group. Published Mar, 2020. Accessed Dec 9, 2020. https://methods. cochrane.org/rapidreviews/sites/methods.cochrane.org.rapidreviews/ files/public/uploads/cochrane_rr_-_guidance-23mar2020-final.pdf

7. Moher D, Hopewell S, Schulz KF, et al. CONSORT 2010 explanation and elaboration: updated guidelines for reporting parallel group randomised trials. BMJ. 2010;340:c869.

8. Quigley JM, Thompson JC, Halfpenny NJ, Scott DA. Critical appraisal of nonrandomized studies-a review of recommended and commonly used tools. J Eval Clin Pract. 2019;25(1):44-52.

9. Davies A, Thompson KA, Giri K, Kafatos G, Walker J, Bennett A. Testing the efficacy of homemade masks: would they protect in an influenza pandemic? Disaster Med Public Health Prep. 2013;7(4):413-418.

10. Liu Z, Yu D, Ge Y, et al. Understanding the factors involved in determining the bioburdens of surgical masks. Ann Transl Med. 2019;7(23):754.

11. Rengasamy S, Eimer B, Shaffer RE. Simple respiratory protection-evaluation of the filtration performance of cloth masks and common fabric materials against 20-1000 nm size particles. Ann Occup Hyg. 2010;54(7):789-798.

12. van der Sande M, Teunis $P$, Sabel R. Professional and home-made face masks reduce exposure to respiratory infections among the general population. PLoS One. 2008;3(7):e2618.

13. Furuhashi M. A study on the microbial filtration efficiency of surgical face masks--with special reference to the non-woven fabric mask. Bull Tokyo Med Dent Univ. 1978;25(1):7-15.

14. Ma QX, Shan H, Zhang HL, Li GM, Yang RM, Chen JM. Potential utilities of mask-wearing and instant hand hygiene for fighting SARS-CoV-2. J Med Virol. 2020;92(9):1567-1571.

15. Quesnel LB. The efficiency of surgical masks of varying design and composition. Br J Surg. 1975;62(12):936-940.

16. Sellers RF, Donaldson Al, Herniman KA. Inhalation, persistence and dispersal of foot-and-mouth disease virus by man. J Hyg (Lond). 1970;68(4):565-573.

17. Maclntyre $C R$, Seale $H$, Dung TC, et al. A cluster randomised trial of cloth masks compared with medical masks in healthcare workers. BMJ Open. 2015;5(4):e006577.

18. Maclntyre $C R$, Wang $Q$, Seale $H$, et al. A randomized clinical trial of three options for $\mathrm{N} 95$ respirators and medical masks in health workers. Am J Respir Crit Care Med. 2013;187(9):960-966. 
19. Maclntyre CR, Wang Q, Cauchemez S, et al. A cluster randomized clinical trial comparing fit-tested and non-fit-tested N95 respirators to medical masks to prevent respiratory virus infection in health care workers. Influenza Other Respir Viruses. 2011;5(3):170-179.

20. American Hospital Association. 100 million mask challenge. Accessed Apr 8, 2020. https://www.100millionmasks.org/

21. Bae S, Kim M-C, Kim JY, et al. Effectiveness of surgical and cotton masks in blocking SARS-CoV-2: a controlled comparison in 4 patients. Ann Intern Med. 2020;173(1):W22-W23. [Retracted in: Ann Intern Med. 2020;173(1):79]

22. Leung NHL, Chu DKW, Shiu EYC, et al. Respiratory virus shedding in exhaled breath and efficacy of face masks. Nat Med. 2020;26(5): 676-680. [Author correction in: Nat Med. 2020;26(6):981]

23. Besser R, Fischoff B. Rapid expert consultation on the effectiveness of fabric masks for the COVID-19 pandemic. In: Rapid Expert Consultations on the COVID-19 Pandemic: March 14, 2020-April 8, 2020. National Academies of Sciences, Engineering, and Medicine; 2020.

24. Eikenberry SE, Mancuso M, Iboi $E$, et al. To mask or not to mask: modeling the potential for face mask use by the general public to curtail the COVID-19 pandemic. Infect Dis Model. 2020;5:293-308.

25. Chu DK, Akl EA, Duda S, Solo K, Yaacoub S, Schünemann HJ; COVID-19 Systematic Urgent Review Group Effort (SURGE) study authors. Physical distancing, face masks, and eye protection to pre- vent person-to-person transmission of SARS-CoV-2 and COVID-19: a systematic review and meta-analysis. Lancet. 2020;395(10242): 1973-1987.

26. World Health Organization. Transmission of SARS-CoV-2: implications for infection prevention precautions. Published Jul 9, 2020. Accessed Dec 14, 2020. https://www.who.int/news-room/ commentaries/detail/transmission-of-sars-cov-2-implications-forinfection-prevention-precautions

27. Braun CC, Foust JW. Behavioral response to the presence of personal protective equipment: implications for risk compensation. Proceedings of the Human Factors and Ergonomics Society Annual Meeting. 1998;42(15):1058-1062.

28. Centers for Disease Control and Prevention. Using personal protective equipment (PPE). Updated Aug 19, 2020. Accessed Dec 9, 2020. https://www.cdc.gov/coronavirus/2019-ncov/hcp/using-ppe.html

29. Centers for Disease Control and Prevention. Considerations for wearing masks. Published 2020. Updated Dec 7, 2020. Accessed Dec 11, 2020. https://www.cdc.gov/coronavirus/2019-ncov/prevent-gettingsick/cloth-face-cover-guidance.html 